\title{
Atypical Chemokine Receptor 3 (ACKR3): A Comprehensive Overview of its Expression and Potential Roles in the Immune System
}

\author{
(1)Joyce Koenen, ${ }^{2}$ ๑) Françoise Bachelerie, ${ }^{3}$ ๑Karl Balabanian, ${ }^{1,3}$ ๑ Géraldine Schlecht-Louf, ${ }^{3}$ \\ and (1)Carmen Gallego ${ }^{2}$
}

INSERM UMR996_-Inflammation, Chemokines and Immunopathology, Université Paris-Sud and Université Paris-Saclay, Clamart, France (J.K., F.B., K.B., G.S.-L., C.G.) and Division of Medicinal Chemistry, Amsterdam Institute for Molecules, Medicines and Systems (AIMMS), Vrije Universiteit Amsterdam, Amsterdam, The Netherlands (J.K.)

Received December 14, 2018; accepted April 24, 2019

\section{ABSTRACT}

Atypical chemokine receptor 3 (ACKR3), previously known as C-X-C chemokine receptor type 7 (CXCR7), has emerged as a key player in several biologic processes, particularly during development. Its CXCL11 and CXCL12 scavenging activity and atypical signaling properties, together with a new array of other nonchemokine ligands, have established ACKR3 as a main regulator of physiologic processes at steady state and during inflammation. Here, we present a comprehensive review of ACKR3 expression in mammalian tissues in search of a possible connection with the receptor function. Besides the reported roles of ACKR3 during development, we discuss the potential contribution of ACKR3 to the function of the immune system, focusing on the myeloid lineage.

\section{Introduction}

This review focuses on the trio formed by C-X-C motif chemokine ligand (CXCL)12 and its two receptors, C-X-C chemokine receptor (CXCR)4 and CXCR7/ACKR3, with particular emphasis on the latter, which belongs to the atypical chemokine receptor subfamily. Since the 1990s, with CXCR4 being discovered as a coreceptor for HIV entry (Feng et al., 1996), the CXCL12/CXCR4 axis has been extensively studied in numerous homeostatic and pathologic settings, including organogenesis, leukocyte trafficking, and cancer. Atypical

This mini-review is part of the mini-review series entitled "From Insight to Modulation of CXCR4 and ACKR3 (CXCR7) Function." This research was funded by the European Union's Horizon 2020 MSCA Program [Grant agreement 641833 ONCORNET] to all authors, by European Union's InfectERA project HPV-Motiva [ANR-15-IFEC-0004-0] to F.B. and G.S.-L., and by a PRC ANR Grant OSTEOVALYMPH [17-CE14-0019] coordinated by K.B. All authors are members of the LabEx LERMIT supported by ANR grant [ANR10-LABX-33] under the program "Investissements d'Avenir" [ANR-11-IDEX0003-01]. C.G. is beneficiary of a fellowship from Fondation de la Recherche Medicale (FRM).

${ }^{1}$ Current affiliation: Université de Paris, Institut de Recherche Saint Louis, EMiLy, Inserm U1160, F-75010 Paris, France.

${ }^{2}$ J.K. and C.G. contributed equally to this work.

${ }^{3}$ F.B., K.B., and G.S.-L. contributed equally to this work.

https://doi.org/10.1124/mol.118.115329. chemokine receptor (ACKR)3 was first known as an orphan receptor named receptor dog cDNA 1, or RDC1 (Heesen et al., 1998), and was later adopted into the chemokine receptor family as CXCR7, the second receptor for CXCL12 (Balabanian et al., 2005) and also CXCL11 (Burns et al., 2006), before being renamed ACKR3 owing to its atypical non-G-protein-dependent signaling (Bachelerie et al., 2014). Since then, compelling evidence has underscored the regulatory function of ACKR3 on the CXCL12/CXCR4 signaling axis. Initial studies in zebrafish models revealed that ACKR3 acts as a scavenger receptor that binds and internalizes CXCL12, thus indirectly modulating CXCR4 function by modifying chemokine bioavailability (Dambly-Chaudière et al., 2007; Valentin et al., 2007; Boldajipour et al., 2008; Donà et al., 2013). Additionally, ACKR3 may have direct functions in response to CXCL12 as a $\beta$-arrestin-biased signaling receptor (Rajagopal et al., 2010), although $\beta$-arrestin-mediated signaling downstream of ACKR3 remains to be demonstrated in vivo. Furthermore, with the identification of new nonchemokine ligands, including macrophage migration inhibitory factor (MIF) or intermediate opioid peptides, ACKR3 has emerged as a key player in homeostatic processes during embryogenesis and adult life but also in pathologic inflammatory and tumor contexts.

ABBREVIATIONS: ACKR3, atypical chemokine receptor 3; BM, bone marrow; CXCL11, C-X-C motif chemokine ligand 11; CXCL12, C-X-C motif chemokine ligand 12; CXCR4, C-X-C chemokine receptor type 4; CXCR7, C-X-C chemokine receptor type 7; EGFP, enhanced green fluorescent protein; ERK, extracellular signal-regulated kinase; HSC, hematopoietic stem cell; MIF, macrophage migration inhibition factor. 
Here, we first summarize the state of the art on ACKR3 expression regarding human and rodent tissues and its role in development before discussing its potential contribution to the function of the immune system. In particular, we focus on myeloid cells, both at homeostasis and in pathologic settings, including inflammatory conditions and breast cancer.

\section{ACKR3 Expression in Mammalian Tissue}

To address the question of ACKR3 expression, mice have been genetically modified to investigate in which cells and tissues the Ackr3 promoter is active (Table 1). These mouse models include replacement of the endogenous Ackr3 coding region by either a $\beta$-galactosidase ( $L a c Z$ ) reporter (Gerrits et al., 2008) or an enhanced green fluorescent protein (EGFP) sequence (Cruz-Orengo et al., 2011). These models also include the Ackr3-EGFP bacterial artificial chromosome mouse model, where an Ackr3 promoter$E G F P$ fusion sequence was inserted into a random location in the genome. In this case, EGFP expression is driven by Ackr3 promoter activity while leaving the endogenous
Ackr3 locus intact (Gong et al., 2003; Sánchez-Alcañiz et al., 2011).

In parallel, several groups have investigated Ackr3 expression at the transcriptional level by means of northern blot, real-time polymerase chain reaction, or in situ hybridization (Table 2) and at the protein level by means of immunofluorescence, immunohistochemistry, or flow cytometry (Table 2). Ackr3 mRNA is mostly detected in mouse heart, kidney, spleen, lung, and brain (Table 2) and is transiently expressed during embryogenesis, in accordance with different reporter mouse models (Table 1). To summarize, by combining various techniques, ACKR3 mRNA and protein have been detected 1) in mesenchymal stromal cells; 2) in brain-resident cells, including astrocytes, glial, and neuronal cells, 3) in cells of the vascular system and, more specifically, cells from vascular smooth muscle and venous endothelium; and of particular interest 4) in immune cell populations. In the immune system, ACKR3 mRNA is detected using transcriptomic approaches in hematopoietic lineages, in both lymphoid (e.g., B cells) and myeloid (e.g., macrophages) cells; however, in EGFP reporter mouse models, the Ackr3 promoter-dependent signal cannot be distinguished from background in any of the studied

\section{TABLE 1}

Genetically modified mouse models to study Ackr3 expression in vivo and associated phenotypes






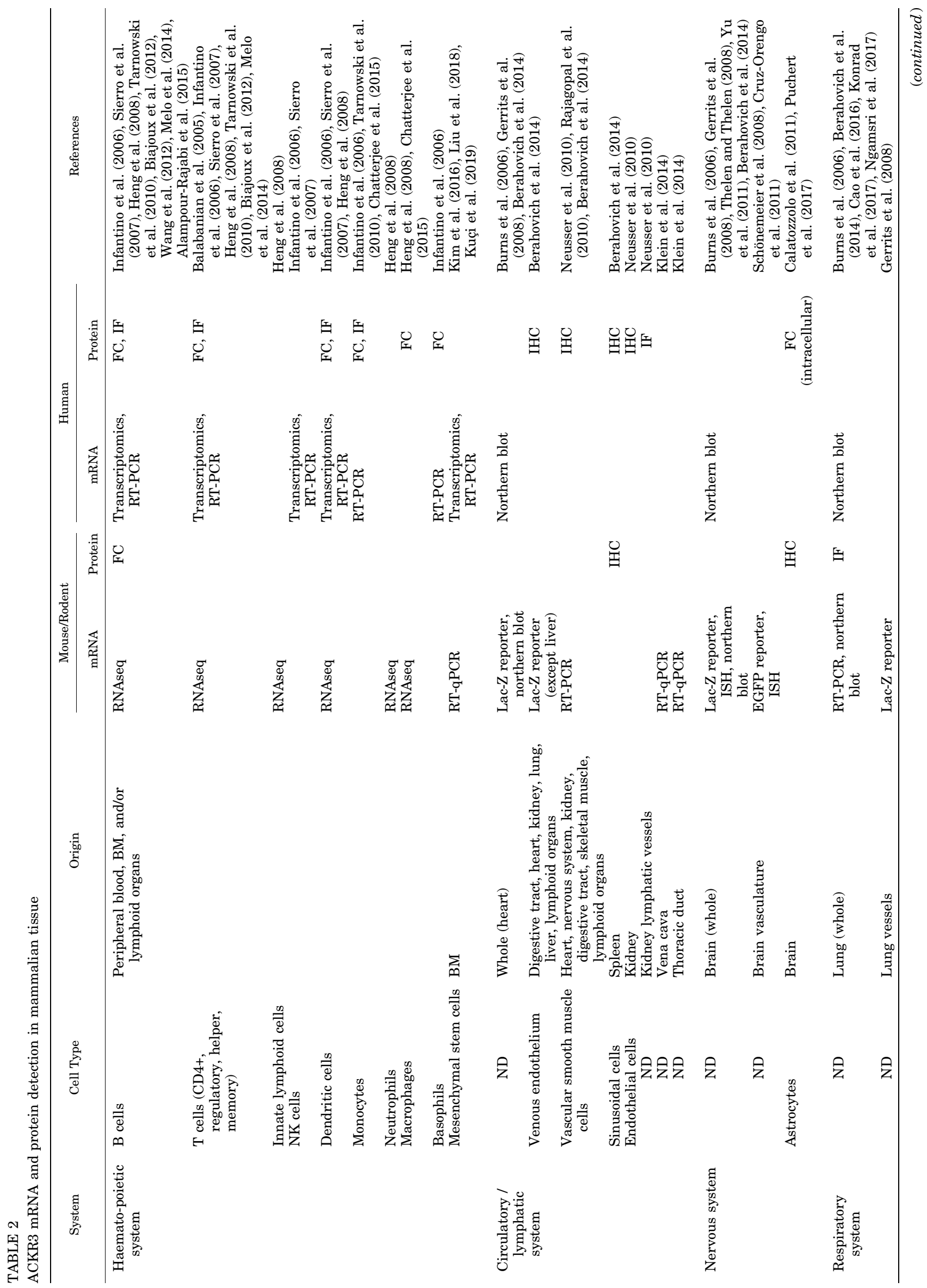


immune cell subsets in steady state (i.e., CD45 ${ }^{+}, \mathrm{CD} 19^{+}$ B cells, $\mathrm{CD}^{+}$and $\mathrm{CD}^{+}{ }^{+} \mathrm{T}$ cells, $\mathrm{CD} 11 \mathrm{~b}^{+}$and $\mathrm{CD} 11 \mathrm{c}^{+}$myeloid cells) (Cruz-Orengo et al., 2011). This was confirmed in LacZ mouse models (Berahovich et al., 2014). Furthermore, assessing ACKR3 protein expression in native conditions poses a technical challenge from its constitutive recycling between the membrane and the endosomal compartment, leading to a predominant intracellular localization. This is a limitation for antibody generation and validation (Berahovich et al., 2010a) and a potential source of discrepancies reported in studies related to ACKR3 expression and function. For instance, ACKR3 protein was not detected either in human and mouse leukocyte subsets in peripheral blood (Berahovich et al., 2010); however, ACKR3 protein was detected in human secondary lymphoid organ-derived B cells and dendritic cells (Infantino et al., 2006).

\section{ACKR3 Function: From Genetically Modified Mice to Nonchemokine Ligands}

Determining when and where ACKR3 is expressed has led to greater understanding of the functions that ACKR3 might be exerting. In particular, the expression pattern of ACKR3 may hint toward a functional role in such cells or tissues. These functions could have a direct effect on ACKR3-expressing cells either through noncanonical signaling pathways or modulation of CXCR4 functions or in a paracrine way via the modulation of CXCL12 and CXCL11 levels, impacting nearby-cell function through CXCR4 and CXCR3, respectively. Valuable information about the function of ACKR3 was first provided by an analysis of the effects after constitutive and cell-type conditional Ackr3 gene deletion in various mouse models (Table 1). Subsequently, identification of other nonchemokine ligands has broadened our understanding of ACKR3 biology, particularly in terms of the role of ACKR3 beyond the chemokine system. In the following section, we discuss how the study of knockout mouse models and nonchemokine ligands has led to further insights into the functions of ACKR3.

Lessons from Constitutive and Conditional Knockout Models. Most Ackr3 $3^{-1-}$ mice develop normally in early embryonic stages but die either perinatally or in utero in late developmental stages, usually from embryonic gestation day E17.5, owing to cardiovascular complications (Sierro et al., 2007; Yu et al., 2011; Trousse et al., 2015). Accordingly, it seems that ACKR3, similarly to CXCR4 and CXCL12, is essential to normal mouse development and physiology and that it plays a complementary or nonredundant role with regard to CXCR4; however, the lethal phenotype obtained in the $\mathrm{C} 57 \mathrm{Bl} / 6$ background is less severe on a mixed genetic background (129 Sv/Evbrd x $\mathrm{C} 57 \mathrm{Bl} / 6$ ) with a survival rate of approximately $30 \%$ (Gerrits et al., 2008). This might be linked to CXCL11-associated ACKR3 functions because expression of this chemokine ligand is absent in C57Bl/6 mice (Sierro et al., 2007). Considering the cardiovascular and cerebral defects observed in Ackr3-deficient mice, a large body of work has focused on ACKR3 contribution to heart and brain physiology. During both heart and brain development, Ackr3 undergoes a change in expression pattern after E14.5, 
which coincides with the onset of mouse death (Sierro et al., 2007; Gerrits et al., 2008; Sánchez-Alcañiz et al., 2011; Wang et al., 2011; Yu et al., 2011).

Two studies suggest that a link may exist between Ackr3 expression and the control of cell proliferation in heart tissue. For example, in constitutive Ackr $3^{-/-}$mice, increased cell proliferation prevented heart-valve thinning that leads to a lethal cardiovascular phenotype (Yu et al., 2011). Moreover, in another study, $25 \%$ of surviving adult $A c k r 3^{-/-}$mice suffered from cardiac hyperplasia (Gerrits et al., 2008). Of note, migration and apoptosis of semilunar valve mesenchymal cells remained normal from E14 to E18.5 in Ackr $3^{-1-}$ mice. In contrast, during brain development, constitutive and conditional loss of Ackr3 in GABAergic neurons (Table 1) led to an abnormal distribution of interneurons in the cortex, suggesting a link between Ackr3 expression and neuron migration (Sánchez-Alcañiz et al., 2011; Wang et al., 2011; Trousse et al., 2015). ACKR3 could have a cell intrinsic function as suggested by extracellular signal-regulated kinase (ERK)1/2 phosphorylation in cultured neurons, likely downstream of ACKR3 (Wang et al., 2011); however, it remains to be determined whether ACKR3-mediated ERK1/2 phosphorylation occurs in vivo and whether it is relevant during brain development. Alternatively, the role of ACKR3 in interneuron positioning could occur through cell-extrinsic effects as a scavenger receptor. Ackr3 deficiency results in increased CXCL12 protein levels but unchanged $\mathrm{Cxcl12}$ mRNA levels in cortical homogenates (Sánchez-Alcañiz et al., 2011). Failure to maintain a CXCL12 gradient leads to accumulation of migrating interneurons in inappropriate locations in the cortex. Moreover, the abnormal distribution of interneurons was rescued when $A c k r 3^{-/-}$interneurons were transplanted into Ackr3 ${ }^{+/+}$ brain, suggesting that ACKR3 expression in other cells can rescue the phenotype (Sánchez-Alcañiz et al., 2011). Furthermore, a recent report has provided mechanistic insights into ACKR3-mediated CXCL12 endocytosis in interneurons by demonstrating that receptor phosphorylation was required for this process, whereas $\beta$-arrestins were dispensable (Saaber et al., 2019). Together, these findings in Ackr3-deficient mice support a role for ACKR3 as a scavenging receptor, particularly in the brain. Even though no obvious defects in the immune system were found in these mouse models, this aspect was not fully explored in the studies, implying that a knowledge gap might exist in this field (discussed in Potential Role of ACKR3 within the Immune System at Steady State and during Inflammation).

Microenvironment-Dependent Functions of ACKR3 and Nonchemokine Ligands. Differences observed in heart and brain tissues in $A c k r 3^{-1-}$ mice can, at least partially, be explained by the microenvironment having an impact on the biologic effects exerted by ACKR3. ACKR3 tissue-dependent functioning might be related to its capacity to interact with several ligands and therefore could be dependent on the surrounding cells producing or processing such ligands. First, within the chemokine system, CXCL12 displays six isoforms in humans and three in mice owing to alternative splicing. These isoforms have different C-terminal extensions and different expression patterns and functions [discussed in Janssens et al. (2018)]. Second, CXCL12 isoforms are processed post-translationally by the microenvironment, producing forms of CXCL12 with different binding and signaling properties on CXCR4 and ACKR3 (Peng et al.,
2012; Janssens et al., 2017, 2018; Szpakowska et al., 2018b). Additionally, the microenvironment changes during disease conditions. For example, CXCL11, which is a ligand for CXCR3, as well as for ACKR3, is normally not detectable in physiologic conditions but an inflammatory context, in which cytokines such as interferon are produced, can induce CXCL11 expression (Flier et al., 2001; Müller et al., 2010; Van Raemdonck et al., 2015; Singh et al., 2016). This implies that ACKR3 function may vary in pathologic conditions compared with steady state (Fig. 1), adding another layer of complexity. Lastly, ACKR3 tissuedependent functions likely depend on the presence of other reported endogenous ligands of ACKR3 outside the chemokine system, including MIF (Alampour-Rajabi et al., 2015), intermediate opioid peptides (Ikeda et al., 2013), and possibly proteins in the adrenomedullin pathway (Klein et al., 2014).

MIF is an inflammatory cytokine that lacks the structural requirements to qualify as a chemokine; however, a previous study has suggested it should be considered as a pseudo-CXC chemokine (Bernhagen et al., 2007) as it binds with high affinity to $\operatorname{CD} 74\left(\mathrm{~K}_{\mathrm{d}} \approx 9 \mathrm{nM}\right), \operatorname{CXCR2}\left(\mathrm{K}_{\mathrm{d}} \approx 1.4\right.$ $\mathrm{nM}), \mathrm{CXCR} 4\left(\mathrm{~K}_{\mathrm{d}} \approx 19.8 \mathrm{nM}\right)$, and to ACKR3 in the nanomolar range ( $\mathrm{K}_{\mathrm{d}}$ not determined) (Leng et al., 2003; Alampour-Rajabi et al., 2015; Bernhagen, 2018). MIF has a physiologic role as a chemoattractant (Bernhagen et al., 2007) and is involved in innate and adaptive immune responses by promoting macrophage activation and B-cell survival (Gore et al., 2008). Moreover, MIF is a mediator in several inflammatory conditions and cancers in an autocrine and paracrine manner by promoting tumor growth (Nobre et al., 2017) and inducing metastasis through CXCR4 (Dessein et al., 2010). Furthermore, MIF/ACKR3 signaling has been studied in platelets, where it prevents apoptosis (Chatterjee et al., 2014), providing evidence for a role of ACKR3 in the hematopoietic system.

Intermediate opioid peptides, such as BAM22, are produced in the adrenal cortex by subcapsular cell hyperplasia cells, and BAM22 has been shown to displace CXCL12 from ACKR3 $\left(\mathrm{IC}_{50}=32.2 \mathrm{nM}\right.$ ) (Szpakowska et al., 2018a). The BAM22/ACKR3 signaling axis has a critical role in the modulation of circulating glucocorticoids, which occurs through the increase of the amplitude of adrenocorticotropic hormone-induced glucocorticoid diurnal oscillation in females (Ikeda et al., 2013). ACKR3 is highly expressed in the adrenal glucocorticoid-producing cells, especially in female mice compared with males, in support of the sex differences of the BAM22/ACKR3-dependent glucocorticoid oscillations.

Finally, adrenomedullin is a peptide hormone involved in angiogenesis and is implicated in cardiovascular diseases. A link between adrenomedullin and ACKR3 pathways may exist on the basis that haploinsufficiency of adrenomedullin partially rescued the lethal defects in $A c k r 3^{-/-}$mice by normalizing the cardiac hyperproliferation (Klein et al., 2014). ACKR3 was suggested as an adrenomedullin scavenger, but a recent article showed that adrenomedullin does not displace CXCL12 from ACKR3 within the $6 \mathrm{pM}$ to $1 \mu \mathrm{M}$ range (Szpakowska et al., 2018a); however, the presence of ACKR3 inhibited canonical adrenomedullin signaling (Klein et al., 2014), suggesting a crosstalk between adrenomedullin and ACKR3 pathways that remains to be fully explored. 


\section{Steady state}
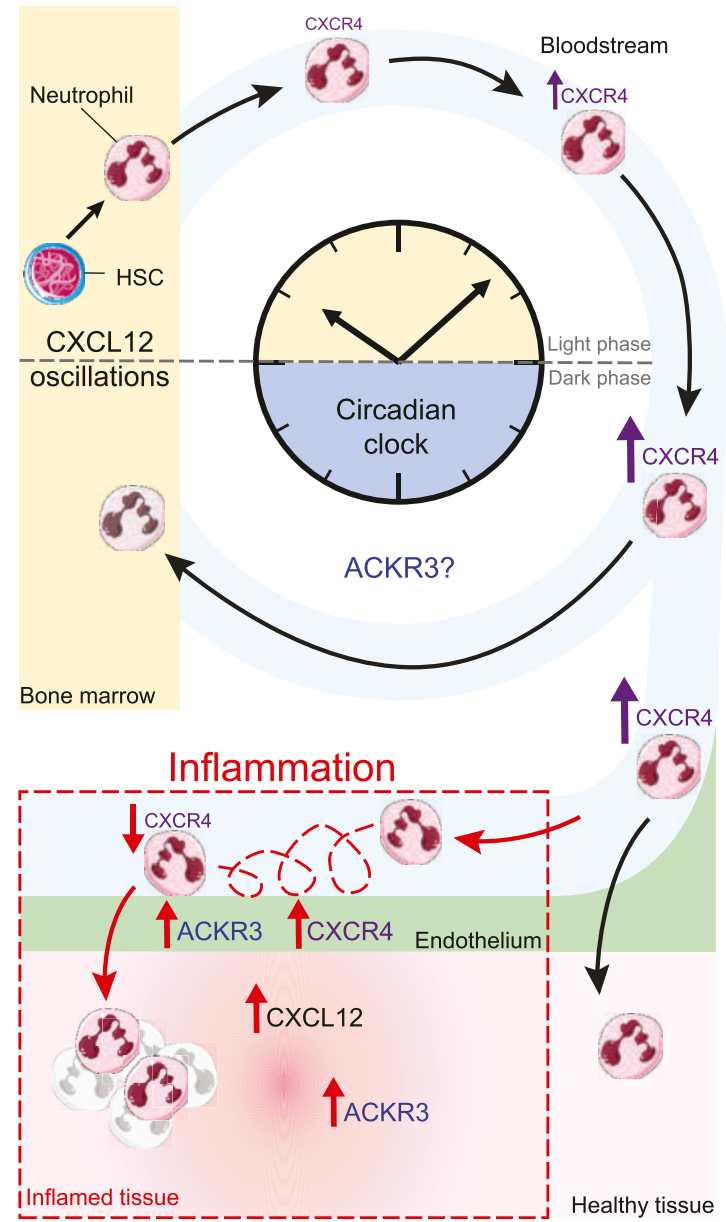

Fig. 1. Potential roles of ACKR3 in steady state and inflammation within the myeloid cell compartment. Neutrophils are produced in bone marrow (BM) from hematopoietic stem cells during granulopoiesis. They are released into the bloodstream after circadian oscillations and increase their surface CXCR4 expression while aging over time. After approximately 12 hours in circulation, at the end of the dark phase, aged CXCR $4^{\text {high }}$ neutrophils migrate back to BM to be eliminated. As part of their patrolling function, they can migrate into healthy tissues. The role of ACKR3 is unknown at steady state, but it could potentially contribute to either the circadian oscillations of CXCL12 within BM via its scavenging activity or to the rhythmic release of neutrophils. When circulating neutrophils encounter inflammatory signals, they can adhere and roll on endothelium and extravasate from the bloodstream to infiltrate inflamed tissue, where they accumulate. Inflammation leads to an upregulation of CXCL12 within the tissue as a cue to attract immune cells. Furthermore, during inflammation, CXCR4 and ACKR3 are upregulated on endothelium as shown in lung inflammatory conditions. In addition, ACKR3 is reported to be upregulated in inflamed tissue (for example in lung alveolar epithelium upon lung inflammation), but its role in CXCL12-level regulation and subsequent immune cell recruitment is not completely understood.

\section{Potential Role of ACKR3 within the Immune System at Steady State and during Inflammation}

The absence of obvious immune-hematopoietic defects in the available $A c k r 3^{-1-}$ mouse models does not exclude a role for ACKR3 in the immune system. Evidence suggests that the CXCL12/CXCR4 signaling axis can regulate the function of the immune system, notably by controlling immune cell subset migration and compartmentalization (Wei et al., 2006; Balabanian et al., 2012) or hematopoietic stem cell (HSC) homing, retention, and quiescence in bone marrow (BM)
(Sugiyama et al., 2006). ACKR3 mRNA and protein are also expressed in certain immune cell subsets, such as B cells and myeloid cells, as reported by several groups (Table 2). ACKR3 might also be involved in the circadian oscillation of CXCL12 expression levels, which regulate immune cell trafficking from and to BM (Fig. 1). In a similar manner to glucocorticoids, CXCL12 transcript and protein levels rhythmically oscillate in BM with light/dark cycles (Katayama et al., 2006; MéndezFerrer et al., 2008, 2010). This oscillation regulates retention in and mobilization from BM of CXCR4-expressing HSCs, which are released during sleep when CXCL12 levels are low and return to BM when CXCL12 levels have increased again (Méndez-Ferrer et al., 2010). CXCL12 is produced by osteoblasts in the bone fraction, endothelial cells around both endosteal and vascular niches, and perivascular mesenchymal stromal cells in the marrow fraction, with the latter representing a major contributor to the CXCL12 pool (Itkin et al., 2016). Depending on the production site, CXCL12 regulates either HSC maintenance or retention (Itkin et al., 2016; Asada et al., 2017). Considering that the ACKR3 scavenging function shapes CXCL12 gradients, the contribution of ACKR3 to the circadian oscillation of CXCL12 levels remains an open question (Fig. 1). Although most of this evidence relates to CXCL12/CXCR4 function, they indirectly point toward a role for ACKR3 in some processes within the immune system, both at steady state and in inflammatory settings. In the following sections, we explore this apparent knowledge gap focusing on myeloid cells.

Potential Role for ACKR3 in the Myeloid Compartment at Steady State. Myeloid cells, such as neutrophils, dendritic cells, or monocytes, are key players in innate immunity, and CXCL12/CXCR4 tightly regulates their homeostasis (De Filippo and Rankin, 2018), particularly their retention in $\mathrm{BM}$ and functioning in peripheral tissues (Chong et al., 2016; Evrard et al., 2018). CXCL12 promotes the extravasation of monocytes and their in vitro differentiation (Sánchez-Martín et al., 2011; Chatterjee et al., 2015), as well as the egress of plasmacytoid dendritic cells from BM (Chopin et al., 2016). Among myeloid cells, neutrophils are the most abundant type in peripheral blood. They are produced and released from BM after daily oscillations; consequently, neutrophil numbers in circulation vary during light/dark cycles (Ella et al., 2016). Neutrophils have a short lifespan in circulation ( 12 hours) and when senescent, "aged" neutrophils express high levels of CXCR4, allowing them to migrate back to BM to be eliminated in a process called clearance (Fig. 1) (Casanova-Acebes et al., 2013). Their egress from BM might be partly due to changes in CXCL12 levels with the circadian rhythms (Méndez-Ferrer et al., 2008; Ella et al., 2016), as described for HSCs; however, other mechanisms may account for neutrophil release as it precedes CXCL12 oscillations (Casanova-Acebes et al., 2013). Recently, clock genes have been described as intrinsic aging regulators in neutrophils in combination with CXCR2 and CXCR4 (Adrover et al., 2019). Disruption of the aging process has consequences on immune cell trafficking at steady state and immune defense against infection. Although ACKR3 is detected in neutrophils, further studies are needed to determine its expression levels during neutrophil maturation and its possible contribution to this process. There is also a case for exploring whether cells of the microenvironment (e.g., cells in BM niches) express ACKR3 and how these factors could be related to neutrophil biology. 
ACKR3 and the Myeloid Compartment in Inflammatory Settings. ACKR3 expression is usually faint or undetectable at steady state in the endothelium and in myeloid cells, but it can be upregulated during inflammation, for instance, by proinflammatory cytokines, such as interleukin8 (Singh and Lokeshwar, 2011) or IL-1 $\beta$ in vitro (Watanabe et al., 2010) and by environmental cues, such as lipopolysaccharide (Cao et al., 2016; Konrad et al., 2017; Ngamsri et al., 2017) or during infection by oncoviruses [reviewed in Freitas et al. (2014)]. Along this line, ACKR3 is highly upregulated during monocyte-to-macrophage differentiation in vitro, switching to a more pro-inflammatory cell phenotype (Ma et al., 2013; Chatterjee et al., 2015). Another example can be found during central nervous system inflammation, where ACKR3 is upregulated in endothelial cells of the blood-brain barrier (Cruz-Orengo et al., 2011). Antagonizing the scavenging activity of ACKR3 using small-molecule CCX771 blocked leukocyte infiltration in the parenchyma, including that of $\mathrm{CD} 1 \mathrm{~b}^{+}$myeloid cells, preventing chronic inflammation and therefore improving disease recovery (Cruz-Orengo et al., 2011). This could be associated with a restoration of the CXCL12 polarity along the blood-brain barrier, which is essential for its integrity and for preventing infiltration of $\mathrm{CXCR}^{+}$cells (McCandless et al., 2008).

Furthermore, the role of ACKR3 has been explored in pulmonary inflammation regarding the lung epithelial barrier function and the recruitment of myeloid cells (Fig. 1). In an acute inflammation mouse model induced by lipopolysaccharide inhalation, ACKR3 protein is upregulated in the lung tissue, both in epithelial and endothelial cells (Ngamsri et al., 2017); however, in chronic lung injury, mouse models induced upon repeated bleomycin injection or hydrochloric acid inhalation, ACKR3 mRNA and protein levels are decreased in endothelial cells (Cao et al., 2016). These findings indicate that ACKR3 may play a role in the early stages of inflammation. Interestingly, in acute inflammation, CXCL12 mRNA and total protein levels in lung homogenates were increased (Cao et al., 2016; Konrad et al., 2017; Ngamsri et al., 2017), and at least mRNA levels remained high in chronic inflammatory settings (Cao et al., 2016). Regarding immune cell recruitment, neutrophils were recruited to the lung tissue in acute inflammation (Konrad et al., 2017; Ngamsri et al., 2017), whereas macrophages were recruited in chronic inflammation (Cao et al., 2016); however, these studies did not explore neutrophil and macrophage recruitment in both short- and long-term inflammatory processes. Pharmacologic modulation of ACKR3 with either CCX771 (Ngamsri et al., 2017) or TC14012 (Cao et al., 2016) prevented microvascular permeability and further alveolar epithelial damage. Although both molecules induce $\beta$-arrestin recruitment to ACKR3, to our knowledge, the downstream signaling pathways have not been assessed (Zabel et al., 2009; Montpas et al., 2015). These molecules can be considered functional antagonists b ecause of their capacity to displace CXCL12 from ACKR3, thus inhibiting the decoy activity of the receptor. Whereas the potential therapeutic benefit of targeting ACKR3 is promising, it cannot be claimed so far which function of ACKR3 contributes to disease improvement (i.e., as a signaling or scavenging receptor). It will be essential to determine where ACKR3 is being expressed using reporter mouse models to decipher its potential protective or proinflammatory role in central nervous system and pulmonary inflammatory diseases.
Lastly, chronic inflammation can promote the progression of cancer (Hanahan and Weinberg, 2011) and is often initiated and maintained by infiltrating immune cells that secrete cytokines and chemokines in the tumor microenvironment (Nagarsheth et al., 2017). For example, in breast cancer, the microenvironment likely induces myeloid-derived suppressor cells that contribute to immune evasion and consequently sustain tumor growth [reviewed in Markowitz et al. (2013)]. CXCL12 also plays an important role in breast cancer. Indeed, CXCL12 production by cancer-associated fibroblasts enhances proliferation and survival of cancer cells, as well as tumor growth and angiogenesis (Orimo et al., 2005). Additionally, CXCL12 facilitates tumor cell intravasation by affecting vasculature integrity (Ahirwar et al., 2018) and contributes to immune evasion by recruitment of $\mathrm{T}$ cells, which differentiate into immunosuppressive regulatory $\mathrm{T}$ cells in the tumor (Su et al., 2017; Costa et al., 2018). Furthermore, sites in the body that constitutively display high concentrations of CXCL12, such as lung or BM, are common metastatic destinations for breast cancer cells (Müller et al., 2001). Interestingly, blockade of CXCR4 with antagonist AMD3100 in breast cancer mouse models reduced the number of immunosuppressive regulatory $\mathrm{T}$ cells and neutrophils in the tumor, improving the immunosuppressive microenvironment (Chen et al., 2019). CXCR4 blockade further reduced activated cancer-associated fibroblasts numbers and increased the transcription of genes associated with antitumor immunity, such as Ifng and Gzma in the tumor mass.

ACKR3 is upregulated in several types of cancer, including breast cancer, frequently in tumor-associated vasculature, as well as in the primary tumors (Freitas et al., 2014). The clinical relevance of ACKR3 in breast cancer has been discussed elsewhere as a part of the mini-review series "From Insight to Modulation of CXCR4 and ACKR3 (CXCR7) Function" (Neves et al., 2019). Studies using mouse orthotopic xenografts suggest that ACKR3 might play a role in maintaining proliferation in the primary tumor while decreasing intravasation of tumor cells and thus reducing metastasis (Hernandez et al., 2011). Furthermore, ACKR3 endothelial expression is likely involved in preventing breast cancer metastasis (Stacer et al., 2016). Collectively, these findings highlight the dual role of ACKR3 either expressed in the primary tumor or in the tumor-associated vasculature. Further research is warranted to understand the underlying mechanisms of ACKR3 that impact the different stages of breast cancer progression and whether this occurs through ACKR3 itself or via modulation of the CXCL12/CXCR4 axis. ACKR3 could shape CXCL12 (and likely CXCL11) availability within the tumor owing to its scavenging activity, which could decrease tumor cell intravasation and metastasis as reported (Hernandez et al., 2011; Stacer et al., 2016; Ahirwar et al., 2018) and potentially immune cell infiltration. In essence, decreasing CXCL12 availability could inhibit CXCR4 responses and thus reverse the immunosuppressive microenvironment in breast cancer, including reduced Treg and increased cytotoxic T-cell numbers.

\section{Discussion}

After being deorphaned in 2005, CXCR7 was proposed to act as an atypical chemokine receptor, ACKR3, with its primary role as a decoy receptor for CXCL12 and CXCL11, whose 
function was to merely internalize the ligands. Over the years, accumulating evidence has supported the concept of ACKR3 being a major regulator of the CXCL12/CXCR4 axis and possibly CXCL11/CXCR3. Furthermore, in some cell lines ACKR3 displays $\beta$-arrestin-biased signaling capacity in vitro in response to its chemokine and non-chemokine ligands, an observation mainly supported by $\beta$-arrestin recruitment and ERK1/2 phosphorylation studies (Zabel et al., 2009; Rajagopal et al., 2010; Wang et al., 2011; Alampour-Rajabi et al., 2015); however, ERK1/2 phosphorylation has not been formally demonstrated to be $\beta$-arrestin-mediated for ACKR3 and particularly in in vivo settings. Moreover, this concept has recently been challenged, as a panel of known $\beta$-arrestinbiased receptors unexpectedly required functional $\mathrm{G}$ proteins to elicit ERK1/2 phosphorylation activity, whereas $\beta$-arrestins were not essential (Grundmann et al., 2018). This result can be highly relevant to ACKR3, which is already known to engage with, but not activate, $\mathrm{G}$ proteins (Levoye et al., 2009). In addition, studies on CRISPR-Cas9-mediated $\beta$-arrestin knockout cell lines have shown that $\beta$-arrestins might not be necessary for ERK1/2 phosphorylation (Luttrell et al., 2018). Instead, they may act as regulators that fine-tune ERK1/2 phosphorylation, depending on the cell type and its strength in potentiating G-protein or $\beta$-arrestin-mediated signaling (Luttrell et al., 2018). Together, these recent findings raise questions about the molecular mechanisms by which ACKR3 is exerting its still underappreciated functions in homeostatic processes (e.g., in hormonal and neuronal systems and potentially in the hematopoietic system).

To conclude, ACKR3 expression and function in immune cells remain poorly understood, and future research should focus on: 1) unambiguously characterizing the ACKR3 expression patterns in physiologic and pathologic contexts; 2) clarifying the mechanisms by which ACKR3 acts as a signaling or a scavenging receptor; and 3) understanding its function in homeostatic processes, such as the circadian oscillation of CXCL12 levels or neutrophil trafficking, as well as in pathologic conditions (Fig. 1). Importantly, inflammation-related pathologic conditions can highly dysregulate ACKR3 expression. Thus, mechanistically deciphering the precise contribution of ACKR3 to immune cell recruitment in inflammatory context should identify ACKR3 as a novel therapeutic target in various diseases and cancer.

\section{Authorship Contributions}

Wrote or contributed to the writing of the manuscript: Koenen, Bachelerie, Balabanian, Schlecht-Louf, Gallego.

Note Added in Proof-The current affiliation of the third author was changed from that used for the Fast Forward version published April 30, 2019.

\section{References}

Abe P, Wüst HM, Arnold SJ, van de Pavert SA, and Stumm R (2018) CXCL12mediated feedback from granule neurons regulates generation and positioning of new neurons in the dentate gyrus. Glia 66:1566-1576.

Adrover JM, Del Fresno C, Crainiciuc G, Cuartero MI, Casanova-Acebes M, Weiss LA, Huerga-Encabo H, Silvestre-Roig C, Rossaint J, Cossío I, et al. (2019) A neutrophil timer coordinates immune defense and vascular protection. Immunity 50: 390-402.e10.

Ahirwar DK, Nasser MW, Ouseph MM, Elbaz M, Cuitiño MC, Kladney RD, Varikuti S, Kaul K, Satoskar AR, Ramaswamy B, et al. (2018) Fibroblast-derived CXCL12 promotes breast cancer metastasis by facilitating tumor cell intravasation. Oncogene 37:4428-4442.

Alampour-Rajabi S, El Bounkari O, Rot A, Müller-Newen G, Bachelerie F, Gawaz M, Weber C, Schober A, and Bernhagen J (2015) MIF interacts with CXCR7 to promote receptor internalization, ERK1/2 and ZAP-70 signaling, and lymphocyte chemotaxis. FASEB J 29:4497-4511.

Asada N, Kunisaki Y, Pierce H, Wang Z, Fernandez NF, Birbrair A, Ma'ayan A, and Frenette PS (2017) Differential cytokine contributions of perivascular haematopoietic stem cell niches. Nat Cell Biol 19:214-223.

Bachelerie F, Graham GJ, Locati M, Mantovani A, Murphy PM, Nibbs R, Rot A Sozzani S, and Thelen M (2014) New nomenclature for atypical chemokine receptors. Nat Immunol 15:207-208.

Balabanian K, Brotin E, Biajoux V, Bouchet-Delbos L, Lainey E, Fenneteau O, Bonnet D, Fiette L, Emilie D, and Bachelerie F (2012) Proper desensitization of CXCR4 is required for lymphocyte development and peripheral compartmentalization in mice. Blood 119:5722-5730.

Balabanian K, Lagane B, Infantino S, Chow KYC, Harriague J, Moepps B, ArenzanaSeisdedos F, Thelen M, and Bachelerie F (2005) The chemokine SDF-1/CXCL12 binds to and signals through the orphan receptor RDC1 in T lymphocytes. J Biol Chem 280:35760-35766.

Berahovich RD, Penfold MET, and Schall TJ (2010a) Nonspecific CXCR7 antibodies. Immunol Lett 133:112-114.

Berahovich RD, Zabel BA, Lewén S, Walters MJ, Ebsworth K, Wang Y, Jaen JC, and Schall TJ (2014) Endothelial expression of CXCR7 and the regulation of systemic CXCL12 levels. Immunology 141:111-122.

Berahovich RD, Zabel BA, Penfold MET, Lewén S, Wang Y, Miao Z, Gan L, Pereda J, Dias J, Slukvin II, et al. (2010b) CXCR7 protein is not expressed on human or mouse leukocytes. J Immunol 185:5130-5139.

Bernhagen J (2018) "Remote" myokine protects from pulmonary ischemia/reperfusion injury by a surprising "proximal" control mechanism. Ann Transl Med 6:275.

Bernhagen J, Krohn R, Lue H, Gregory JL, Zernecke A, Koenen RR, Dewor M, Georgiev I, Schober A, Leng L, et al. (2007) MIF is a noncognate ligand of CXC chemokine receptors in inflammatory and atherogenic cell recruitment. Nat Med 13:587-596.

Biajoux V, Bignon A, Freitas C, Martinez V, Thelen M, Lima G, Jakez-Ocampo J, Emilie D, Llorente L, and Balabanian K (2012) Expression of CXCL12 receptors in $\mathrm{B}$ cells from Mexican Mestizos patients with systemic Lupus erythematosus. J Transl Med 10:251.

Boldajipour B, Mahabaleshwar H, Kardash E, Reichman-Fried M, Blaser H, Minina S, Wilson D, Xu Q, and Raz E (2008) Control of chemokine-guided cell migration by ligand sequestration. Cell 132:463-473.

Burns JM, Summers BC, Wang Y, Melikian A, Berahovich R, Miao Z, Penfold MET, Sunshine MJ, Littman DR, Kuo CJ, et al. (2006) A novel chemokine receptor for SDF-1 and I-TAC involved in cell survival, cell adhesion, and tumor development. J Exp Med 203:2201-2213.

Calatozzolo C, Canazza A, Pollo B, Di Pierro E, Ciusani E, Maderna E, Salce E, Sponza V, Frigerio S, Di Meco F, et al. (2011) Expression of the new CXCL12 receptor, CXCR7, in gliomas. Cancer Biol Ther 11:242-253.

Cao Z, Lis R, Ginsberg M, Chavez D, Shido K, Rabbany SY, Fong G-H, Sakmar TP, Rafii S, and Ding B-S (2016) Targeting of the pulmonary capillary vascular niche promotes lung alveolar repair and ameliorates fibrosis. Nat Med 22:154-162.

Casanova-Acebes M, Pitaval C, Weiss LA, Nombela-Arrieta C, Chèvre R, A-González N, Kunisaki Y, Zhang D, van Rooijen N, Silberstein LE, et al. (2013) Rhythmic modulation of the hematopoietic niche through neutrophil clearance. Cell 153: 1025-1035.

Chatterjee M, Seizer P, Borst O, Schönberger T, Mack A, Geisler T, Langer HF, May AE, Vogel S, Lang F, et al. (2014) SDF-1 $\alpha$ induces differential trafficking of CXCR4-CXCR7 involving cyclophilin A, CXCR7 ubiquitination and promotes platelet survival. FASEB $J$ 28:2864-2878.

Chatterjee M, von Ungern-Sternberg SNI, Seizer P, Schlegel F, Büttcher M, Sindhu NA, Müller S, Mack A, and Gawaz M (2015) Platelet-derived CXCL12 regulates monocyte function, survival, differentiation into macrophages and foam cells through differential involvement of CXCR4-CXCR7. Cell Death Dis 6:e1989.

Chen IX, Chauhan VP, Posada J, Ng MR, Wu MW, Adstamongkonkul P, Huang P, Lindeman N, Langer R, and Jain RK (2019) Blocking CXCR4 alleviates desmoplasia, increases T-lymphocyte infiltration, and improves immunotherapy in metastatic breast cancer. Proc Natl Acad Sci 116:4558-4566.

Chong SZ, Evrard M, Devi S, Chen J, Lim JY, See P, Zhang Y, Adrover JM, Lee B, Tan L, et al. (2016) CXCR4 identifies transitional bone marrow premonocytes that replenish the mature monocyte pool for peripheral responses. J Exp Med 213: $2293-2314$

Chopin M, Preston SP, Lun ATL, Tellier J, Smyth GK, Pellegrini M, Belz GT, Corcoran LM, Visvader JE, Wu L, et al. (2016) RUNX2 mediates plasmacytoid dendritic cell egress from the bone marrow and controls viral immunity. Cell Reports 15:866-878. Costa A, Kieffer Y, Scholer-Dahirel A, Pelon F, Bourachot B, Cardon M, Sirven P, Magagna I, Fuhrmann L, Bernard C, et al. (2018) Fibroblast heterogeneity and immunosuppressive environment in human breast cancer. Cancer Cell 33:463-479.e10.

Cruz-Orengo L, Holman DW, Dorsey D, Zhou L, Zhang P, Wright M, McCandless EE, Patel JR, Luker GD, Littman DR, et al. (2011) CXCR7 influences leukocyte entry into the CNS parenchyma by controlling abluminal CXCL12 abundance during autoimmunity. $J$ Exp Med 208:327-339.

Dambly-Chaudière C, Cubedo N, and Ghysen A (2007) Control of cell migration in the development of the posterior lateral line: antagonistic interactions between the chemokine receptors CXCR4 and CXCR7/RDC1. BMC Dev Biol 7:23.

De Filippo K and Rankin SM (2018) CXCR4, the master regulator of neutrophil trafficking in homeostasis and disease. Eur J Clin Invest 48 (Suppl 2):e12949.

Dessein AF, Stechly L, Jonckheere N, Dumont P, Monté D, Leteurtre E, Truant S, Pruvot FR, Figeac M, Hebbar M, et al. (2010) Autocrine induction of invasive and metastatic phenotypes by the MIF-CXCR4 axis in drug-resistant human colon cancer cells. Cancer Res 70:4644-4654.

Donà E, Barry JD, Valentin G, Quirin C, Khmelinskii A, Kunze A, Durdu S, Newton LR, Fernandez-Minan A, Huber W, et al. (2013) Directional tissue migration through a self-generated chemokine gradient. Nature 503:285-289.

Ella K, Csépányi-Kömi R, and Káldi K (2016) Circadian regulation of human peripheral neutrophils. Brain Behav Immun 57:209-221. 
Evrard M, Kwok IWH, Chong SZ, Teng KWW, Becht E, Chen J, Sieow JL, Penny HL, Ching GC, Devi S, et al. (2018) Developmental analysis of bone marrow neutrophils reveals populations specialized in expansion, trafficking, and effector functions. Immunity 48:364-379.e8.

Feng Y, Broder CC, Kennedy PE, and Berger EA (1996) HIV-1 entry cofactor: functional cDNA cloning of a seven-transmembrane, $\mathrm{G}$ protein-coupled receptor. Science 272:872-877.

Flier J, Boorsma DM, van Beek PJ, Nieboer C, Stoof TJ, Willemze R, and Tensen CP (2001) Differential expression of CXCR3 targeting chemokines CXCL10, CXCL9 and CXCL11 in different types of skin inflammation. J Pathol 194:398-405.

Freitas C, Desnoyer A, Meuris F, Bachelerie F, Balabanian K, and Machelon V (2014) The relevance of the chemokine receptor ACKR3/CXCR7 on CXCL12-mediated effects in cancers with a focus on virus-related cancers. Cytokine Growth Factor Rev 25:307-316.

Gerrits H, van Ingen Schenau DS, Bakker NEC, van Disseldorp AJM, Strik A, Hermens LS, Koenen TB, Krajnc-Franken MAM, and Gossen JA (2008) Early postnatal lethality and cardiovascular defects in CXCR7-deficient mice. Genesis 46 $235-245$.

Gong S, Zheng C, Doughty ML, Losos K, Didkovsky N, Schambra UB, Nowak NJ, Joyner A, Leblanc G, Hatten ME, et al. (2003) A gene expression atlas of the central nervous system based on bacterial artificial chromosomes. Nature 425 : 917-925.

Gore Y, Starlets D, Maharshak N, Becker-Herman S, Kaneyuki U, Leng L, Bucala R, and Shachar I (2008) Macrophage migration inhibitory factor induces B cell survival by activation of a CD74-CD44 receptor complex. J Biol Chem 283:2784-2792.

Grundmann M, Merten N, Malfacini D, Inoue A, Preis P, Simon K, Rüttiger N, Ziegler N, Benkel T, Schmitt NK, et al. (2018) Lack of beta-arrestin signaling in the absence of active G proteins. Nat Commun 9:341.

Hanahan D and Weinberg RA (2011) Hallmarks of cancer: the next generation. Cell 144:646-674.

Heesen M, Berman MA, Charest A, Housman D, Gerard C, and Dorf ME (1998) Cloning and chromosomal mapping of an orphan chemokine receptor: mouse RDC1. Immunogenetics 47:364-370.

Heng TSP and Painter MW; Immunological Genome Project Consortium (2008) The Immunological Genome Project: networks of gene expression in immune cells. Nat Immunol 9:1091-1094.

Hernandez L, Magalhaes MAO, Coniglio SJ, Condeelis JS, and Segall JE (2011) Opposing roles of CXCR4 and CXCR7 in breast cancer metastasis. Breast Cancer Res 13:R128.

Ikeda Y, Kumagai H, Skach A, Sato M, and Yanagisawa M (2013) Modulation of circadian glucocorticoid oscillation via adrenal opioid-CXCR7 signaling alters emotional behavior. Cell 155:1323-1336.

Infantino S, Moepps B, and Thelen M (2006) Expression and regulation of the orphan receptor RDC1 and its putative ligand in human dendritic and B cells. J Immuno 176:2197-2207.

Itkin T, Gur-Cohen S, Spencer JA, Schajnovitz A, Ramasamy SK, Kusumbe AP, Ledergor G, Jung Y, Milo I, Poulos MG, et al. (2016) Distinct bone marrow blood vessels differentially regulate haematopoiesis. Nature 532:323-328.

Janssens R, Mortier A, Boff D, Ruytinx P, Gouwy M, Vantilt B, Larsen O, Daugvilaite V, Rosenkilde MM, Parmentier M, et al. (2017) Truncation of CXCL12 by CD26 reduces its CXC chemokine receptor 4- and atypical chemokine receptor 3-dependent activity on endothelial cells and lymphocytes. Biochem Pharmacol 132:92-101.

Janssens R, Struyf S, and Proost P (2018) Pathological roles of the homeostatic chemokine CXCL12. Cytokine Growth Factor Rev 44:51-68.

Katayama Y, Battista M, Kao WM, Hidalgo A, Peired AJ, Thomas SA, and Frenette PS (2006) Signals from the sympathetic nervous system regulate hematopoietic stem cell egress from bone marrow. Cell 124:407-421.

Kim DS, Ko YJ, Lee MW, Park HJ, Park YJ, Kim D-I, Sung KW, Koo HH, and Yoo $\mathrm{KH}$ (2016) Effect of low oxygen tension on the biological characteristics of human bone marrow mesenchymal stem cells. Cell Stress Chaperones 21:1089-1099.

Klein KR, Karpinich NO, Espenschied ST, Willcockson HH, Dunworth WP, Hoopes SL, Kushner EJ, Bautch VL, and Caron KM (2014) Decoy receptor CXCR7 modulates adrenomedullin-mediated cardiac and lymphatic vascular development. Dev Cell 30:528-540.

Konrad FM, Meichssner N, Bury A, Ngamsri K-C, and Reutershan J (2017) Inhibition of SDF-1 receptors CXCR4 and CXCR7 attenuates acute pulmonary inflammation via the adenosine $\mathrm{A}_{2 \mathrm{~B}}$-receptor on blood cells. Cell Death Dis 8:e2832.

Kuçi S, Kuçi Z, Schäfer R, Spohn G, Winter S, Schwab M, Salzmann-Manrique E, Klingebiel T, and Bader P (2019) Molecular signature of human bone marrowderived mesenchymal stromal cell subsets. Sci Rep 9:1774.

Leng L, Metz CN, Fang Y, Xu J, Donnelly S, Baugh J, Delohery T, Chen Y, Mitchell $\mathrm{RA}$, and Bucala R (2003) MIF signal transduction initiated by binding to CD74 $J$ Exp Med 197:1467-1476.

Levoye A, Balabanian K, Baleux F, Bachelerie F, and Lagane B (2009) CXCR7 heterodimerizes with CXCR4 and regulates CXCL12-mediated G protein signaling. Blood 113:6085-6093.

Liu L, Chen J-X, Zhang X-W, Sun Q, Yang L, Liu A, Hu S, Guo F, Liu S, Huang Y, et al. (2018) Chemokine receptor 7 overexpression promotes mesenchymal stem cell migration and proliferation via secreting chemokine ligand 12. Sci Rep 8:204

Luttrell LM, Wang J, Plouffe B, Smith JS, Yamani L, Kaur S, Jean-Charles P-Y, Gauthier C, Lee M-H, Pani B, et al. (2018) Manifold roles of $\beta$-arrestins in GPCR signaling elucidated with siRNA and CRISPR/Cas9. Sci Signal 11:eaat7650.

Ma W, Liu Y, Ellison N, and Shen J (2013) Induction of C-X-C chemokine receptor type 7 (CXCR7) switches stromal cell-derived factor-1 (SDF-1) signaling and phagocytic activity in macrophages linked to atherosclerosis. J Biol Chem 288:15481-15494.

Maishi N, Ohga N, Hida Y, Akiyama K, Kitayama K, Osawa T, Onodera Y, Shinohara N, Nonomura K, Shindoh M, et al. (2012) CXCR7: a novel tumor endothelial marker in renal cell carcinoma. Pathol Int 62:309-317.

Markowitz J, Wesolowski R, Papenfuss T, Brooks TR, and Carson WE III (2013) Myeloid-derived suppressor cells in breast cancer. Breast Cancer Res Treat 140:13-21.
Mazzinghi B, Ronconi E, Lazzeri E, Sagrinati C, Ballerini L, Angelotti ML, Parente E, Mancina R, Netti GS, Becherucci F, et al (2008) Essential but differential role for CXCR4 and CXCR7 in the therapeutic homing of human renal progenitor cells. $J$ Exp Med 205:479-490.

McCandless EE, Piccio L, Woerner BM, Schmidt RE, Rubin JB, Cross AH, and Klein RS (2008) Pathological expression of CXCL12 at the blood-brain barrier correlates with severity of multiple sclerosis. Am J Pathol 172:799-808.

Melo RCC, Longhini AL, Bigarella CL, Baratti MO, Traina F, Favaro P, de Melo Campos P, and Saad ST (2014) CXCR7 is highly expressed in acute lymphoblastic leukemia and potentiates CXCR4 response to CXCL12 [published correction appears in PLoS One (2014) 9:e91365]. PLoS One 9:e85926.

Méndez-Ferrer S, Lucas D, Battista M, and Frenette PS (2008) Haematopoietic stem cell release is regulated by circadian oscillations. Nature 452:442-447.

Méndez-Ferrer S, Michurina TV, Ferraro F, Mazloom AR, Macarthur BD, Lira SA, Scadden DT, Ma'ayan A, Enikolopov GN, and Frenette PS (2010) Mesenchymal and haematopoietic stem cells form a unique bone marrow niche. Nature 466 $829-834$

Montpas N, Cabana J, St-Onge G, Gravel S, Morin G, Kuroyanagi T, Lavigne P, Fujii $\mathrm{N}$, Oishi S, and Heveker N (2015) Mode of binding of the cyclic agonist peptide TC14012 to CXCR7: identification of receptor and compound determinants. Biochemistry 54:1505-1515.

Müller A, Homey B, Soto H, Ge N, Catron D, Buchanan ME, McClanahan T, Murphy E, Yuan W, Wagner SN, et al. (2001) Involvement of chemokine receptors in breast cancer metastasis. Nature 410:50-56.

Müller M, Carter S, Hofer MJ, and Campbell IL (2010) Review: the chemokine receptor CXCR3 and its ligands CXCL9, CXCL10 and CXCL11 in neuroimmunity--a tale of conflict and conundrum. Neuropathol Appl Neurobiol 36:368-387.

Nagarsheth N, Wicha MS, and Zou W (2017) Chemokines in the cancer microenvironment and their relevance in cancer immunotherapy. Nat Rev Immunol 17: $559-572$.

Neusser MA, Kraus AK, Regele H, Cohen CD, Fehr T, Kerjaschki D, Wüthrich RP, Penfold MET, Schall T, and Segerer S (2010) The chemokine receptor CXCR7 is expressed on lymphatic endothelial cells during renal allograft rejection. Kidney Int 77:801-808.

Neves M, Fumagalli A, van den Bor J, Marin P, Smit MJ, and Mayor F Jr (2019) The role of ACKR3 in breast, lung and brain cancer. Mol Pharmacol 96:819-825.

Ngamsri K-C, Müller A, Bösmüller H, Gamper-Tsigaras J, Reutershan J, and Konrad FM (2017) The pivotal role of CXCR7 in stabilization of the pulmonary epithelial barrier in acute pulmonary inflammation. J Immunol 198:2403-2413.

Nobre CC, de Araújo JM, Fernandes TA, Cobucci RN, Lanza DC, Andrade VS and Fernandes JV (2017) Macrophage migration inhibitory factor (MIF): biological activities and relation with cancer. Pathol Oncol Res 23:235-244.

Orimo A, Gupta PB, Sgroi DC, Arenzana-Seisdedos F, Delaunay T, Naeem R, Carey VJ, Richardson AL, and Weinberg RA (2005) Stromal fibroblasts present in invasive human breast carcinomas promote tumor growth and angiogenesis through elevated SDF-1/CXCL12 secretion. Cell 121:335-348.

Peng H, Wu Y, Duan Z, Ciborowski P, and Zheng JC (2012) Proteolytic processing of SDF- $1 \alpha$ by matrix metalloproteinase- 2 impairs CXCR4 signaling and reduces neural progenitor cell migration. Protein Cell 3:875-882.

Puchert M, Pelkner F, Stein G, Angelov DN, Boltze J, Wagner DC, Odoardi F, Flügel A, Streit WJ, and Engele J (2017) Astrocytic expression of the CXCL12 receptor, CXCR7/ACKR3 is a hallmark of the diseased, but not developing CNS. Mol Cell Neurosci 85:105-118

Rajagopal S, Kim J, Ahn S, Craig S, Lam CM, Gerard NP, Gerard C, and Lefkowitz RJ (2010) Beta-arrestin- but not G protein-mediated signaling by the "decoy" receptor CXCR7. Proc Natl Acad Sci USA 107:628-632.

Saaber F, Schütz D, Miess E, Abe P, Desikan S, Ashok Kumar P, Balk S, Huang K, Beaulieu JM, Schulz S, et al. (2019) ACKR3 regulation of neuronal migration requires ACKR3 phosphorylation, but not $\beta$-arrestin. Cell Reports 26: 1473-1488.e9.

Sánchez-Alcañiz JA, Haege S, Mueller W, Pla R, Mackay F, Schulz S, López-Bendito G, Stumm R, and Marín O (2011) Cxcr7 controls neuronal migration by regulating chemokine responsiveness. Neuron 69:77-90.

Sánchez-Martín L, Estecha A, Samaniego R, Sánchez-Ramón S, Vega MÁ, and Sánchez-Mateos P (2011) The chemokine CXCL12 regulates monocytemacrophage differentiation and RUNX3 expression. Blood 117:88-97.

Schönemeier B, Kolodziej A, Schulz S, Jacobs S, Hoellt V, and Stumm R (2008) Regional and cellular localization of the CXCl12/SDF-1 chemokine receptor CXCR7 in the developing and adult rat brain. J Comp Neurol 510:207-220.

Sierro F, Biben C, Martínez-Muñoz L, Mellado M, Ransohoff RM, Li M, Woehl B, Leung H, Groom J, Batten M, et al. (2007) Disrupted cardiac development but normal hematopoiesis in mice deficient in the second CXCL12/SDF-1 receptor, CXCR7. Proc Natl Acad Sci USA 104:14759-14764.

Singh RK and Lokeshwar BL (2011) The IL-8-regulated chemokine receptor CXCR7 stimulates EGFR signaling to promote prostate cancer growth. Cancer Res $\mathbf{7 1}$ 3268-3277.

Singh UP, Singh NP, Murphy EA, Price RL, Fayad R, Nagarkatti M, and Nagarkatti PS (2016) Chemokine and cytokine levels in inflammatory bowel disease patients. Cytokine 77:44-49.

Stacer AC, Fenner J, Cavnar SP, Xiao A, Zhao S, Chang SL, Salomonnson A, Luker $\mathrm{KE}$, and Luker GD (2016) Endothelial CXCR7 regulates breast cancer metastasis. Oncogene 35:1716-1724

Su S, Liao J, Liu J, Huang D, He C, Chen F, Yang L, Wu W, Chen J, Lin L, et al. (2017) Blocking the recruitment of naive $\mathrm{CD}^{+} \mathrm{T}$ cells reverses immunosuppression in breast cancer. Cell Res 27:461-482.

Sugiyama T, Kohara H, Noda M, and Nagasawa T (2006) Maintenance of the hematopoietic stem cell pool by CXCL12-CXCR4 chemokine signaling in bone marrow stromal cell niches. Immunity 25:977-988.

Szpakowska M, Meyrath M, Reynders N, Counson M, Hanson J, Steyaert J, and Chevigné A (2018a) Mutational analysis of the extracellular disulphide bridges 
of the atypical chemokine receptor ACKR3/CXCR7 uncovers multiple binding and activation modes for its chemokine and endogenous non-chemokine agonists. Biochem Pharmacol 153:299-309.

Szpakowska M, Nevins AM, Meyrath M, Rhainds D, D’huys T, Guité-Vinet F, Dupuis N, Gauthier P-A, Counson M, Kleist A, et al. (2018b) Different contributions of chemokine N-terminal features attest to a different ligand binding mode and a bias towards activation of ACKR3/CXCR7 compared with CXCR4 and CXCR3. $\mathrm{Br} J$ Pharmacol 175:1419-1438.

Tarnowski M, Liu R, Wysoczynski M, Ratajczak J, Kucia M, and Ratajczak MZ (2010) CXCR7: a new SDF-1-binding receptor in contrast to normal CD34(+) progenitors is functional and is expressed at higher level in human malignant hematopoietic cells. Eur J Haematol 85:472-483.

Thelen M and Thelen S (2008) CXCR7, CXCR4 and CXCL12: an eccentric trio? $J$ Neuroimmunol 198:9-13.

Trousse F, Poluch S, Pierani A, Dutriaux A, Bock HH, Nagasawa T, Verdier J-M, and Rossel M (2015) CXCR7 receptor controls the maintenance of subpial positioning of Cajal-Retzius cells. Cereb Cortex 25:3446-3457.

Valentin G, Haas P, and Gilmour D (2007) The chemokine SDF1a coordinates tissue migration through the spatially restricted activation of Cxcr7 and Cxcr4b. Curr Biol 17:1026-1031.

Van Raemdonck K, Van den Steen PE, Liekens S, Van Damme J, and Struyf S (2015) CXCR3 ligands in disease and therapy. Cytokine Growth Factor Rev 26 $311-327$.
Wang H, Beaty N, Chen S, Qi C-F, Masiuk M, Shin DM, and Morse HC III (2012) The CXCR7 chemokine receptor promotes B-cell retention in the splenic marginal zone and serves as a sink for CXCL12. Blood 119:465-468.

Wang Y, Li G, Stanco A, Long JE, Crawford D, Potter GB, Pleasure SJ, Behrens T, and Rubenstein JL (2011) CXCR4 and CXCR7 have distinct functions in regulating interneuron migration. Neuron 69:61-76.

Watanabe K, Penfold MET, Matsuda A, Ohyanagi N, Kaneko K, Miyabe Y, Matsumoto K, Schall TJ, Miyasaka N, and Nanki T (2010) Pathogenic role of CXCR7 in rheumatoid arthritis. Arthritis Rheum 62:3211-3220.

Wei S, Kryczek I, and Zou W (2006) Regulatory T-cell compartmentalization and trafficking. Blood 108:426-431.

Yu S, Crawford D, Tsuchihashi T, Behrens TW, and Srivastava D (2011) The chemokine receptor CXCR7 functions to regulate cardiac valve remodeling. Dev Dyn 240:384-393.

Zabel BA, Wang Y, Lewén S, Berahovich RD, Penfold MET, Zhang P, Powers J, Summers BC, Miao Z, Zhao B, et al. (2009) Elucidation of CXCR7-mediated signaling events and inhibition of CXCR4-mediated tumor cell transendothelial migration by CXCR7 ligands. J Immunol 183:3204-3211.

Address correspondence to: Carmen Gallego, 32 rue des Carnets, 92140 Clamart, France. E-mail: carmen.gallego@u-psud.fr; or Joyce Koenen, 32 rue des Carnets, 92140 Clamart, France. E-mail: joyce.koenen@u-psud.fr 